\title{
SEXOPOLITICA, ESCOLAS E PSICOLOGIA: PELA PRODUCAO DE NARRATIVAS QUE ASSOMBREM
}

Marcelo Santana Ferreira ${ }^{\mathrm{i}}$

O artigo apresenta uma defesa do estatuto político da experiência da infância, relacionando-o com o conceito de sexo política proposto por Paul Beatriz Preciado, no esforço de legitimar práticas de produção de narrativas que não acatem o silenciamento de experiências dissidentes. No artigo, procura-se defender uma posição contemporânea da Psicologia em contextos educacionais em que os temas do gênero e da sexualidade se apresentam como determinantes na definição da experiência da infância e da juventude. Trata-se de artigo que não apenas caracteriza um determinado campo conceitual, como também se articula de forma propositiva.

Palavras-chave: Infância; Sexopolítica; Narrativa.

\section{SEXOPOLITICS, SCHOOLS AND PSYCHOLOGY : FOR THE PRODUCTION OF NARRATIVES THAT HAUNT}

The article presents a defense of the political status of childhood experience, relating it to the concept of sexopolitics proposed by Paul Beatriz Preciado, in the effort to legitimize practices of production of narratives that do not silencing of dissident experiences. In the article, we seek to defend a contemporary position of Psychology in educational contexts in which the themes of gender and sexuality are presented as determinants in the definition of the experience of childhood and youth. It is an article that not only characterizes a certain conceptual field, but also articulates in a propositional way.

Key-words: Childhood; Sexopolitics; Narrative. 
Existem dois caminhos para a moderna ciência psicológica, dentre os múltiplos destinos desde a sua emergência institucional, que são usualmente considerados quando se pensa sobre o devir de ideias psicológicas: o caminho das investigações experimentais e as diferentes controvérsias em torno da cientificidade do saber psicológico e a inserção certeira de racionalidades específicas desenvolvidas em torno da infância, da sexualidade e da loucura em diferentes estabelecimentos modernos, como as escolas, os hospitais, as fábricas e os presídios. Dando ênfase a escola, percebe-se a proeminência de práticas e saberes instrumentalizados por uma perspectiva psicológica, seja no desenvolvimento de tecnologias educativas, seja na tradução da complexidade das instituições em jogo no processo educacional em termos como desenvolvimento cognitivo, afetos e desejo, ou ainda, na abertura considerável de campos investigativos e de aplicação nas escolas modernas para o saber psicológico.

A sexualidade, considerada como um efeito-instrumento de um processo moderno de governo dos indivíduos e das populações em sociedades ocidentais indica a centralidade de uma argumentação desenvolvimentista sobre a formação dos indivíduos, transitando da necessidade de uma regulação efetiva das relações entre adultos e crianças para a proliferação de técnicas e de moralidades que nos ajudaram a compor a imagem que forjamos da infância e da juventude, além de terem sustentado - até o presente momento - nosso modo de nos relacionarmos com crianças e jovens. Vamos considerar, com o apoio de Paul Beatriz Preciado (2011), que estamos enredados numa sexopolitica, que está presente de modo claro e cotidiano não apenas nas representações de crianças e jovens por saberes e práticas instituídas, mas na regulamentação das relações, na regulação dos vínculos e nas práticas de si que são reiteradas pelos próprios sujeitos forjados no fluxo de instituições, discursos e estabelecimentos em que inventamos parte do nosso destino em sociedade. A sexopolitica se espraia como artefatos para crianças e jovens, como políticas de enunciação e de produção de narratividades, como expectativa de temporalidade de formação de si e como pressuposto universalizante de nossas histórias pessoais. No presente artigo, pretende-se apresentar uma abordagem desviante em relação aos pressupostos universalizantes, por intermédio da reconsideração do estatuto da infância como experiência política e do caráter aberto dos termos sexo e gênero na arena política em que gerações se interpelam.

\section{Sexopolítica e Psicologia}

A sexopolítica recoloca a discussão de Michel Foucault em torno do caráter histórico do sexo e da sexualidade, uma vez que não se encerra no entendimento dos anormais produzidos 
pelo dispositivo de sexualidade - que se estrutura como um híbrido de instituições e discursos que forjam e abrigam a experiência sexual ocidental - como efeitos de discurso, na acepção de Preciado (2011). A sexopolítica amplia o sentido histórico de biopolítica, incorporando a radicalidade de lutas contemporâneas que des-ontologizam o sujeito das formações políticas contestatórias e reivindicatórias de direitos. Além disto, a sexopolitica caracteriza, como categoria, o esforço de Preciado (2011) em abrigar o sentido ético e político das experiências de si que não são transcendentes aos contextos históricos em que se formularam as corporeidades ocidentais, brancas e straight. A sexopolítica reivindica o próprio movimento inerente ao percurso da categoria de biopolítica em Michel Foucault, iniciada quando o pensador se debruçou sobre a especificidade de tecnologias políticas formuladas no contexto do liberalismo, instituídas em torno das problemáticas envolvidas na regulação de fenômenos relacionados com o tema da população. A vida possui estatuto político, sobre o próprio fato de sermos seres viventes se exerce um poder de regulação e de maximização da vida. A sexualidade, como instrumento de convergência entre os indivíduos e a população, ocupa lugar privilegiado na regulação. Investindo na vida, a partir do século XVIII, a anatomo-política do corpo humano se complementa com a biopolítica das populações, no desenvolvimento de racionalidades específicas, dentre as quais, os saberes em torno da experiência da infância e da relação entre adultos e crianças. Michel Foucault (1997) defende a categoria de biopolítica, rompendo com a hipótese repressiva utilizada correntemente para se compreender a historicidade da sexualidade. Já a categoria sexopolítica prescreve a espessura política das enunciações dos anormais designados pelo dispositivo de sexualidade, transitando da situação de injúria para a de afirmação de singularidades, de multidões não totalizáveis em unidades abstratas e universalizantes.

A Psicologia como ciência se formula no contexto de consolidação da ciência da sexualidade ocidental, trazendo para si uma das destinações de práticas de confissão, agora remetidas a um escrutínio do "si mesmo" formulado por intermédio de diferentes interpelações. A hipérbole do tema da sexualidade presente no estudo das afecções nervosas foi traduzida, no século XIX, de variadas formas e encontrou na Psicanálise um tratamento diferenciado, embora a perspectiva evolucionista em torno da pulsão sexual também se colocasse. A perspectiva evolucionista-desenvolvimentista sobre a formação do sujeito encontra na Psicologia uma destinação no enquadramento das vivencias individuais. Há o pressuposto de que se alcance a coerência individual adulta na transição por fases de desenvolvimento psico-sexual, em que o caráter político das regulações de sexo e de gênero se faz presente. Muito precocemente se estabelecem os limites e possibilidades da sexualidade, produzindo-se artefatos, como se trata da 
condição da criança e do próprio jovem, em que o destino se impõe como heterossexual, configurado como regulação política, mais do que uma orientação sexual per se.

Considerando que a Psicologia estabelece mecanismos de interpelação reiterados institucionalmente em torno das experiências da infância e da juventude, podemos pensar que se forjam objetos e sujeitos, assentados em arquiteturas e em teleologias desenvolvimentistas. Há uma continuidade entre a materialidade de novos espaços sociais, como as escolas, e as prescrições de condutas e de projetos de vida. A infância, especificamente, emerge como objeto privilegiado de preocupação e tema evocado nas narrativas que adultos formulam sobre seus processos de formação de si. Mas a interpelação não encontra um sujeito prévio, anterior aos próprios procedimentos de interrogação e de problematização de si. Para Pelbart (2013), ao comentar a relação entre experiência e sujeito na obra de Michel Foucault, se trata de abandonar qualquer risco de estruturalismo ao evocar uma exterioridade ao sujeito bem como de fundacionismo ao se pressupor que exista algo como uma subjetividade primeva. A experiência de si complexifica o campo da sexopolitica, uma vez que não se trata simplesmente de submissão ao regime instituído sobre os corpos e os prazeres, mas de possíveis desvios em relação ao que está estabelecido. Sujeito e objeto não param de se modificar no campo da experiência. Crianças e jovens não param de exigir um outro desdobramento da nossa relação com o dispositivo de sexualidade. Sobre a definição do campo de estudos de Michel Foucault, Pelbart (2013) afirma que:

E o que se pode chamar, pois, de uma historia crítica do pensamento, onde o estatuto de um sujeito e de um objeto devem não ser tomados como dados, mas devem ser remetidos a sua constituição histórica, aos modos de subjetivação e de objetivação e sua relação reciproca, conforme certas regras e jogos de verdade. Recusar, portanto, não apenas qualquer universal antropológico, o homem, o louco, o delinquente, o sujeito de uma sexualidade, mas igualmente a exigência de fazer a análise recuar ate o sujeito constituinte, pressuposto e condição últimos de toda a análise.” (p.51).

A sexopolítica está em jogo nas regulações da relação entre adultos, crianças e jovens. A Psicologia se configura como saber privilegiado na interpretação de atos e processos de formação de indivíduos, ao permitir a consideração cronológica das etapas da vida. Mesmo com as preocupações moralistas em torno do corpo de crianças e da preocupação inicial com a conservação das crianças burguesas no século XIX e, futuramente, com a de jovens burgueses para se atingir uma preocupação com as crianças e jovens de classes subalternizadas economicamente e socialmente, crianças e jovens são precocemente convocados a participarem 


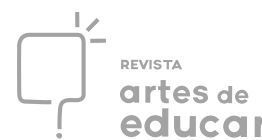

de instituições e práticas em que o tema da sexualidade se densifica. Muito precocemente, a inserção de crianças de forma compulsória na sexopolítica marca as formas de se definir como sujeitos que possuem inteligibilidade, sujeitos aceitáveis na experiência escolar e nos meandros da vida social. Para a Psicologia, ocultar o estatuto histórico dos procedimentos de interpretação da formação dos sujeitos pode significar a repetição da violência cometida em torno de experiências consideradas dissidentes em relação à norma sexual vigente. A dignidade de um exercício crítico em torno da produção de narrativas sobre a formação de si pode se tornar crucial para continuar a defender a relação entre Psicologia, escolas e a articulação de novas narrativas.

As crianças e a infância aparecem de modo duplo em narrativas sobre a formação de si: como objetos privilegiados de governo, uma vez que sabemos que as escolas no nosso país não são simplesmente estabelecimentos de transmissão de conhecimento, mas fundamentalmente de reiteração de princípios de inteligibilidade generificados: o que e e como se comporta uma menina, o que e como se comporta um menino, que prazeres são passíveis de serem aceitos e que outros precisam ser submetidos a desconfiança e cuidado; além disso, a infância é evocada nas narrativas de adultos sobre o seu processo de formação como sujeitos. Um embaraço metodológico se desenha na pretensão de se atingir a infância, experiência recuada no tempo lembrado e experiência objetificada por dispositivos disciplinares. Tal embaraço se complexifica na opacidade do Eu que se põe a narrar sobre si mesmo. Encontramos em Judith Butler (2015) uma fundamental caracterização do paradoxo da narrativa de si:

Assim como existe uma ação performativa e alocutória executada por esse "eu", há um limite ao que o "eu" pode realmente recontar. Esse "eu" se fala e se articula, e ainda que pareça fundamentar a narrativa que conto, ele e o momento mais infundado da narrativa. A única história que o "eu" não pode contar é a história de seu próprio surgimento como "eu" que, além de falar, relata a si mesmo. Nesse sentido, há uma história sendo contada, mas o "eu" que a conta, que pode aparecer nela como narrador em primeira pessoa, constitui um ponto de opacidade e interrompe a sequencia, induz uma quebra ou erupção do não narrável no meio da história. Desse modo, a história que conto de mim mesma, destacando o "eu" que sou e inserindo-o nas sequencias relevantes de uma coisa chamada "minha vida", deixa de relatar a mim mesma no momento em que apareço. Com efeito, apareço como aquela de quem nenhum relato pode ou será dado. Estou fazendo um relato de mim mesma, mas não há relato a ser feito quando se trata da formação desse "eu" que fala e narraria sua vida. Quanto mais eu narro, mais provo ser menos capaz de fazer um relato de mim mesma. O "eu" arruína minha história, apesar de suas melhores intenções”. (p.89). 
Propondo uma espécie de ontologia do narrar e do "dar conta de si mesmo", Butler (2015) acaba apresentando ferramentas conceituais fundamentais para nossa consideração do sentido político da experiência de si em direção a uma defesa de narrativas que assombrem regimes sexuais vigentes e instituições bem estabelecidas em nosso cenário social. O caráter de ruína da história que se pode contar sobre si mesmo converge, magicamente, com as considerações de Walter Benjamin sobre o estatuto político da experiência da infância e da juventude, pois apontam para um reconhecimento dos vestígios da época e dos procedimentos que exigiram certa coerência e modo de se definir como humano. A sexopolítica exige que haja convergência entre práticas sexuais e elaboração de identidades e se traduz na cronologia dos destinos individuais, mas a ruína da história que o Eu pode contar de si mesmo pode encontrar as histórias não reconhecidas no devir de instituições que nos ajudaram a nos definir como sujeitos. Para os estudos do campo da Psicologia, o impacto de tal interpretação precisa ser acolhido, de modo a que possamos, finalmente, apresentar e defender a produção de narrativas que assombrem.

\section{A politica da infância em Walter Benjamin: narrativas que assombram}

Lidar com a infância como elemento primordial da defesa da Erfarhung no contexto da modernidade talvez seja uma perspectiva ousada para se pensar como ainda pode haver experiência em sociedades em que não há mais sabedoria, ou seja, o lado épico da verdade. A experiência da infância se traduz como abrigo do que era resto, como invenção a partir do que restou. Walter Benjamin (2002), mesmo herdando aspectos do Iluminismo em sua obra, buscou caracterizar uma relação não instrumentalizada com a infância, mesmo que idealize, em muitos momentos, as crianças. A criança se configura como uma personagem de sua argumentação em torno da modernidade e, em um dos seus textos sobre livros para crianças no início do século $\mathrm{XX}$, o pensador assim se opõe ao modelo tradicional de escrever livros para crianças:

E ocioso ficar meditando febrilmente na produção de objetos - material ilustrado, brinquedos ou livros - que seriam apropriados as crianças. Desde o Iluminismo e está uma das mais rançosas especulações do pedagogo. Em sua unilateralidade, ele não vê que a Terra está repleta dos mais puros e infalsificáveis objetos da atenção infantil. E objetos dos mais específicos. E que crianças são especialmente inclinadas a buscarem todo local de trabalho onde a atuação sobre as coisas se processa de maneira visível. Sentem-se irresistivelmente atraídas pelos detritos que se originam da construção, do trabalho no jardim ou na marcenaria, da 
atividade do alfaiate ou onde quer que seja. Nesses produtos residuais elas reconhecem o rosto que o mundo das coisas volta exatamente para elas, e somente para elas. Neles, estão menos empenhadas em reproduzir as obras dos adultos do que em estabelecer uma relação nova e incoerente entre restos e materiais residuais. (BENJAMIN, 2002, p. 57$58)$.

Os resíduos do mundo dos adultos são salvos, na brincadeira infantil, da mercantilização das coisas. Quando as coisas são salvas do risco de se tornarem mercadorias, elas próprias voltam um rosto às crianças. As mercadorias se configuram como uma sobreposição do valor de troca em relação ao valor de uso das coisas, um reino de fantasmagorias impostas a adultos tratados como se fossem crianças. A seriedade da experiência infantil não se equivale, na argumentação benjaminiana, ao sentimentalismo burguês e aos projetos de governamentalidade em curso nas relações assimétricas entre adultos e crianças no contexto pedagógico tradicional. A seriedade da experiência não se encaminha a perspectiva de que a infância seja uma espécie de sensibilidade "em si”, uma vez que se trata de uma posição em relação ao que se oferece. O que resta da experiência infantil se encaminha em relação com a própria ruína de unidade e de estabilidade do mundo imaginado por adultos. Em texto de juventude, posteriormente revisto exatamente no contexto do entre-guerras, Walter Benjamin (2002) já anunciava a preocupação político-filosófica com a experiência almejada pelos adultos: apagamento da grandiosidade das coisas. A experiência, de acordo com o texto originalmente escrito em 1913, havia se tornado o evangelho dos filisteus, os adultos rancorosos e sentimentalistas, saudosos da inocência que supunham haver nas crianças:

Tudo o que tem sentido, o verdadeiro, o bem, o belo está fundamentado em si mesmo - o que a experiência tem a ver com tudo isso? E aqui está o segredo: uma vez que o filisteu jamais levanta os olhos para as coisas grandes e plenas de sentido, a experiência transformou-se em seu evangelho. Ela converte-se para ele na mensagem da vulgaridade da vida. (BENJAMIN, 2002, p.22).

A consideração de que a experiência também possa ser definida conceitualmente como compartilhamento, ainda vai precisar dos materiais problemas enfrentados a partir da perseguição nazista sofrida pelo pensador judeu alemão para que assuma uma posição significativa em sua obra. No contexto citado anteriormente, se tratava de se posicionar politicamente em relação ao esvaziamento da intensidade como projeto da extensividade estrita da experiência filisteia. A infância se caracteriza como confronto com os interesses instituídos dos adultos e da sociedade capitalista, preocupada, hegemonicamente, com finalidades como 
posição respeitável, coerência, desconsolo, seriedade pedante. Em texto escrito originalmente em 1929, Benjamin (2002) volta a se preocupar com modelos pedagógicos em relação à infância, recorrendo a uma distinção célebre entre a condição de uma criança burguesa e a de uma criança proletária, distinção que precisa ser contemplada seriamente para se pensar novos modelos educacionais. Afirma Benjamin (2002):

A burguesia encara a sua prole enquanto herdeiros; os deserdados, porém, a encaram enquanto apoio, vingadores ou libertadores. Está e uma diferença suficientemente drástica. Suas consequências pedagógicas são incalculáveis. (p.122).

A aproximação a filosofia marxista garante ainda mais espessura política e histórica a discussão sobre modelos pedagógicos em Walter Benjamin. Sem abrir mão definitivamente de uma metafísica da juventude e de uma idealização da infância, trata-se, também, de uma busca por referencias antropológicas materialistas a respeito da experiência da infância. Prosseguindo em sua discussão, Benjamin (2002) ainda afirma que se trata de um estatuto diferenciado da percepção infantil quando se refere a situações de classe distintas:

(...) a pedagogia proletária não parte de duas datas abstratas, mas de uma concreta. A criança proletária nasce dentro de sua classe. Mais exatamente, dentro da prole de sua classe, e não no seio da família. Ela é, desde o inicio, um elemento dessa prole, e não é nenhuma meta educacional doutrinária que determina aquilo que essa criança deve tornar-se, mas sim a situação de classe. Esta situação penetra-a desde o primeiro instante, já no ventre materno, como a própria vida, e o contato com ela está inteiramente direcionado no sentido de aguçar desde cedo, na escola da necessidade e do sofrimento, sua consciência. (p.122).

A discussão anterior indica a centralidade da realidade histórica e política para a definição de infância em Walter Benjamin. Voltando-se para o estatuto de confronto da brincadeira, o pensador não se esquece de defender que a própria percepção infantil possui densidade política: o mundo se apresenta de modo diferenciado para quem nasce no seio de uma família e para quem nasce no cerne de uma classe. A contribuição benjaminiana também se dirige ao caráter precário da lembrança quando se dedica a defender um olhar sobre o século XIX por intermédio de recordações de infância. Já não se trata de recuperar algo que diga respeito ao próprio Walter Benjamin, especificamente. Mas que se dirige ao apelo do caráter inescapável de perda, quando se fala de infância. Aquilo que lembramos, aquilo que está definitivamente perdido. 


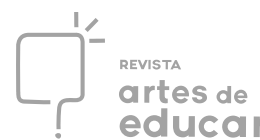

A perda da transparência do eu se coloca como princípio metodológico e político para uma crítica a posição soberana do sujeito sobre os acontecimentos históricos. A infância e a juventude são categorias históricas, não correspondem, de forma definitiva, a características universais de seres humanos em seu processo evolutivo. A duplicidade do estatuto da infância em Walter Benjamin - como experiência politica e como mediação postergada na relação com os acontecimentos do passado - nos permite avançar na defesa de que narrativas que assombrem a sexopolítica contemporânea indicam a fertilidade das ruínas das categorias de infância e juventude. Para isso, será necessário identificar dois tipos de narratividades que interrogam, imediatamente, a inteligibilidade heterosssexista como a única que possua legitimidade. Os dois tipos de narratividades podem, assim, ser resumidas como:

a) Primeiramente, torna-se importante afirmar que narratividades são formas de enunciação que não se assentam na autoridade plena de um narrador, mas se compõem como textos em que se pode reconhecer a proveniência de instituições sociais e de exercícios de si a partir ou apesar das exigências de determinadas instituições, como aquelas que subsidiam os estabelecimentos escolares. Neste sentido, narratividades podem ser memórias que evocam experiências escolares, textos acadêmicos, literários ou jornalísticos em que o tema da educação e da escola assumam importância significativa em relação a problemática da elaboração de si mesmo como sujeito;

b) Após a definição inicial de narratividades, tratar-se-a, na discussão proposta, de fragmentos de textualidades em que tanto se designa a infância e a juventude, como se articula um lugar enunciativo a partir da infância e da juventude. Vamos as textualidades.

Textualidade 1 - Benjamin (2013) escreve um importante texto sobre memórias de infância que pode nos servir como subsídio para uma crítica imanente a suposta segurança de uma experiência transparente ou evidente da infância. A autobiografia se articula como o confronto com um lugar inassumível ética e metodologicamente. Por que isso seria importante na presente discussão? Existem procedimentos que forjam possibilidades de enunciação e a elaboração de personagens. A infância considerada como experiência política não se disponibiliza como fase. Trata-se, fundamentalmente, de certa forma de relação com o tempo. Em Benjamin (2013), encontramos:

\section{A caixa de leitura}

Jamais poderemos reaver inteiramente o esquecido. E isso talvez seja bom. O choque da recuperação seria tão destruidor que nesse mesmo instante teríamos de deixar de entender a nossa nostalgia. E dessa maneira, porem, que a entendemos, e tanto melhor quanto mais fundo se acha em nós o esquecido. Tal como a palavra perdida, que ainda agora tínhamos na ponta da língua, lhe daria asas demostenicas, assim também 
o esquecido parece ter em si o peso da promessa de toda a vida vivida. (p.149).

Mas também encontramos em Gagnebin (1994) o comentário sobre a dissolução da centralidade do Eu que supostamente coordenaria o processo de retomada de imagens do passado. No caso de Benjamin, se trataria de um conjunto de aspectos do final do século XIX em Berlim, no cerne de uma experiência burguesa, que poderiam nos servir de instrumento para o reconhecimento daquilo que se extinguiu. Ao final do processo, no entanto, percebemos tratar-se da designação de fragmentos do passado em que o narrador não pode encontrar a origem absoluta de si mesmo, mas a multiplicação de possibilidades de compreender a proveniência de instituições e de características de si que jamais poderiam ser apreendidas no recuo do tempo, mas no "agora" de uma cognoscibilidade que não abdica de uma relação com o esquecimento. Afirma Gagnebin (1994) que:

(...) Benjamin insiste várias vezes na sua tentativa de captar, de reter imagens nas quais uma experiência muito maior que o vivido consciente e individual do narrador se depositou: a experiência da grande cidade tal como ela se apresenta a uma criança da classe burguesa, no inicio do século [século XX] , e isto apesar de todas as estratégias familiares e sociais para esconder a existência dos outros, dos pobres e dos revoltados, da miséria e da morte. (p.91).

A promessa de toda a vida vivida tinha um caráter preciso na história pessoal do pensador judeu alemão: a nostalgia da cidade natal, a vivência de quem, talvez, nunca retorne a esta cidade. Mais do que encerrar a imagem no âmbito privado da nostalgia, trata-se, também, de expressar a íntima conexão com experimentações estéticas e politicas progressistas do século $\mathrm{XX}$. Mais do que isso, a provisoriedade e incompletude do narrador remete-se as instituições que forjam um lugar para as crianças, mais próximas dos vencidos, silenciadas, submetidas a uma administração. Não seria este o caso das existências dissidentes as normas de sexualidade e de gênero?

A possibilidade de atravessar aspectos pessoais de uma vivência e alcançar os regimes instituídos em torno do gênero e da sexualidade se configura como matéria fecunda para uma analítica da administração da infância e da juventude em contextos específicos, como os que se desenrolam na America Latina. Giancarlo Cornejo (2011) em sua proposição de uma "autoetnografia" recupera fragmentos de estabelecimentos sociais interessados na regulação de seus movimentos e no processo de elaboração de si, sempre desqualificado por ser um menino afeminado. Muito precocemente, crianças são submetidas a regimes de inteligibilidade, 
fragilizando-se as estratégias coletivas de enfrentamento das idealizações sobre os processos de conquista de autonomia e de coerência pessoais. Em uma perspectiva de defesa da infância, como se maximiza contemporaneamente no Brasil, são as vivências malditas e dissidentes de si as primeiras a serem encaminhadas aos especialistas, servindo de modelo para uma reiteração melancólica de um estilo de gênero. Cornejo (2011) não deve sentir saudade dos tempos de infância, submetidos, na materialidade do texto acadêmico, a um exercício de escrutínio político e afetivo:

En la escuela había una sicóloga que me torturaba constantemente. Nos hacía exámenes cuyo sentido no entendía - ni aún hoy lo entendo -. Teníamos que dibujar a personas, a nuestras familias, hacíamos listas de nuestros defectos y virtudes. Ella siempre se quejaba con mis padres. Recuerdo que una vez los mandó a llamar y quevi claramente en su cuaderno de apuntes mi nombre y al costado una $X$ en una opción que decía "problemas de identidad sexual". No estuve presente cuando ella converso con mis padres, pero lo que les dijo, que yo más o menos intuía, les molesto mucho. (p.85).

A "autoetnografia" sugerida por Cornejo dialoga, a partir da textualidade do material acadêmico e político, com a suspensão das emoções evidentes da infância em um país da América Latina, o Peru. A memória do pesquisador se encontra com momentos dos quais se tem vergonha, hoje. Ele e seu irmão riram demoradamente dos lábios de uma enfermeira negra. Do que riam? Hoje, na urgência de reconhecimento da compulsoriedade do dispositivo de sexualidade que submete a totalidade das vivências pessoais ao modelo da coerência e da identidade heterossexual, Cornejo (2011) articula uma metodologia que identifica como violências insuspeitas também eram cometidas por quem não sabia muito bem que também era um problema para os profissionais da educação. A infância já se encontra submetida aos cânones do dispositivo de sexualidade que institui visibilidades e dizibilidades. Ter sobrevivido a isso remete ao sentido político dos processos de elaboração de si: do que rimos no passado, do que nos envergonhamos hoje? A textualidade indica parte da violência cometida cotidianamente sobre existências consideradas ininteligíveis, necessitadas de correção.

Textualidade 2 - A pesquisadora Luma Nogueira de Andrade (2015) ao narrar sua formação como educadora indica a magnitude da escola em um processo de rebaixamento de suas vivências pessoais. A trajetória da educadora-travesti está impregnada por uma desqualificação das suas atitudes. Tornar-se a educadora de hoje só se torna possível por intermédio de um reposicionamento em relação ao que se padeceu na escola. A própria Andrade (2015) narra: 
Durante minha infância, o acontecimento que mais marcou minha vida ocorreu quando eu cursava a segunda série do primeiro grau (equivalente ao terceiro ano do atual Ensino Fundamental). Durante o recreio, quando brincava com as minhas colegas de "elástico" e "macaquinha", fui agredida fisicamente a socos e pontapés por um colega de sala que enquanto me batia me mandava "ser homem". Mesmo estando bem machucada, consegui me livrar do colega e me dirigi chorando para a sala, fiquei em minha carteira, de cabeça baixa, sendo consolada por algumas de minhas amigas. Ao perceber que a professora se aproximava, uma das garotas lhe delatou o agressor no intuito de reprimir aquele colega. Mas ela não disse nada, não fez nada contra ele, apenas ficou diante de minha carteira, me olhou da cabeça aos pés e disse: "Bem feito! Quem manda você ser assim?”. (p.54).

Uma narratividade que assombra os ideais de inclusão e de homogeneização nas escolas contemporâneas, ainda mais frágeis no contexto do nosso país. A naturalidade com que acatamos a temporalidade da formação da identidade heterossexual fragiliza a experiência da dissidência, garantindo condições para sofrimentos individuais que podem inviabilizar a continuidade de processos de escolarização e de eventuais modificações nos destinos sociais de sujeitos desqualificados. Uma narratividade como a citada não pode ser simplesmente constatada. $\mathrm{O}$ paradigma da coerência individual heterossexual se assenta na violência cometida as minorias sexuais e de gênero. A infância se torna o substrato oclusivo das politicas de gênero. Muitas crianças morrerão, as que sobrevivem exigem outra política de formação. A contribuição de Walter Benjamin (2013) mais uma vez pode nos apoiar na tentativa de politização das experiências de si dissidentes as normas de gênero e de sexualidade. Ao se debruçar sobre fragmentos de infância - textualidades que se aproximam da materialidade da própria cidade evocada nas imagens do final do século XIX em Berlim - Benjamin (2013) considera o lugar dos desajeitados, mencionando a personagem do anão corcunda na apreensão de sua desatenção, frisada pelos adultos. Assim se narra em Benjamin (2013):

Foi a minha mãe quem me disse. "Já chegou o desastrado!", dizia ela quando eu quebrava alguma coisa ou caia. Agora entendo o que ela queria dizer. Referia-se ao anãozinho corcunda que tinha olhado para mim. Aqueles para quem ele olha não dão atenção ao que fazem. Nem a si, nem ao corcundinha. Ficam encavacados diante de um monte de cacos. "Quis ir a minha cozinha/ Fazer a sopa, e já nela/ Me espera um anão corcunda/ P'ra me partir a panela.”. Onde ele aparecesse, quem ficava a perder era eu.". (p.114). 
Ao interpretar a figura do anão corcunda como expressão da personagem dos ajudantes nos contos de fada, Agamben (2007) amplia o alcance da reflexão de Benjamin, indicando o lugar do esquecimento na ontologia de nos mesmos:

O ajudante [...] se refere a tudo que, na vida coletiva e na vida individual, acaba sendo esquecido em todo instante, a massa interminável do que acaba irrevogavelmente perdido. Em cada instante, a medida de esquecimento e de ruína, o desperdício ontológico que trazemos em nos mesmos excedem em grande medida a piedade de nossas lembranças e da nossa consciência. Mas esse caos informe do esquecido, que nos acompanha como um golem silencioso, não é inerte nem ineficaz, mas, pelo contrário, age em nós com força não inferior a das lembranças conscientes, mesmo que de forma diferente. Há uma força e quase uma apóstrofe do esquecido, que não podem ser medidas em termos de consciência, nem acumuladas como um patrimônio, mas cuja insistência determina a importância de todo saber e de toda consciência.” (p.35).

Os desajeitados de gênero, as crianças que não aprendem, a criança que se tornou educadora na transformação da injúria em parte inalienável de sua identidade. As narratividades da infância assombram ideais estabelecidas, imperceptíveis como engrenagem do dispositivo nominalista da sexualidade: mesmo sem o saber, permitimos que a brincadeira infantil seja medida pelas regulações de gênero e de sexualidade. Mesmo assim, na escola se aprende a ser forte, a forjar para si e para os outros um outro modo de viver. Andrade (2015) nos conta:

Mesmo em um ambiente escolar de negação da minha forma de brincar e de ser, eu tinha um projeto que superava a dor física e psicológica que vivenciava diariamente, era estudar e aprender, objetivando conseguir um bom emprego para ajudar minha família. (p.57).

E ainda prossegue:

(...) para me sentir protegida, tanto na escola pública quanto na particular, me relacionava diretamente com amigos homossexuais, pois nos sentíamos mais protegidos e menos solitários em grupo. A escola foi o lugar mais importante e exclusivo para minha socialização com pessoas homossexuais; foi nesse espaço que realizei descobertas e me encontrei, até me permitir extravasar meus sentimentos, discutindo sobre minha sexualidade e desejos íntimos com amigos homossexuais. (p.63).

Conquistando o "espaço escolar", Andrade (2015) transforma a injúria. Nem todos os indivíduos possuem a mesma resiliência, mas aqui se trata de um trabalho pessoal e político, uma vez que as violências ainda prosseguem e toda possibilidade de conhecimento e de ultrapassagem se assenta, inicialmente, na representação daquilo que configura a ontologia da 


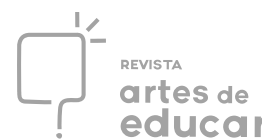

consciência: o esquecido não se reitera apenas no trauma, mas persiste como definição do que se torna inesquecível. O que temos feito com crianças dissidentes e com jovens dissidentes nas escolas interrompe toda defesa dos estabelecimentos escolares como espaços seguros. As crianças desajeitadas e os jovens desajeitados são silenciados, desqualificados, empurrados para a negação e o sofrimento. Mesmo que o "sem jeito" implique na definição da própria possibilidade de se relacionar com as coisas de forma não mercantil (as coisas também possuem a sua contrapartida em relação ao anãozinho corcunda que Benjamin (2013) conheceu no Livro Infantil Alemão), para nós, o "sem jeito" nos encaminha ao reconhecimento das exigências exaustivas do dispositivo de sexualidade. Desatentas ao fato de que, ao brincarmos, somos diagnosticados como inteligíveis ou ininteligíveis, as crianças desajeitadas indicam o alto preço que a heterossexualidade compulsória nos cobra. Para muitos, a própria vida. As narrativas de infância são felizes?

\section{Conclusões provisórias sobre narrativas que ainda assombram}

As narrativas que assombram nossos estabelecimentos de ensino, as regras estabelecidas em torno das brincadeiras infantis e nossas exigências de unidade e de coerência em relação a experiência de si na infância e na juventude precisam ser multiplicadas no exercício crítico acerca das possibilidades interventivas para a Psicologia no espaço escolar e nos projetos educacionais. Produzir narratividades que assombram, ficar atento as narratividades que assombram. Desde a definição de que a ciência histórica esteja mais próxima da arte de contar histórias do que do modelo teórico que preside as ciências naturais na primeira metade do século $\mathrm{XX}$, Walter Benjamin reconhece o valor das narrativas na abordagem intensiva do tempo histórico, avessa ao tratamento cronológico de fatos. Trata-se, justamente, de uma nova atenção ao que não havia sido reconhecida no passado, uma das imagens possíveis que concerne, exatamente, ao presente. As narrativas que assombram interferem na concepção de infância e de juventude, garantindo um lugar a caducidade da lembrança e a opacidade do Eu. Imiscuindo-se na vida de crianças e jovens, as moralidades vigentes e os saberes subalternos as mesmas moralidades administram o terror cotidiano da produção de vidas ininteligíveis.

O esforço contemporâneo de parte da Psicologia pode se encaminhar a compreensão da produção de inteligibilidade nas práticas em torno da infância e da juventude. Já temos condições políticas e epistemológicas de considerar o estatuto contingente da experiência da infância e da juventude, o que não inviabiliza a efetividade de técnicas e de projetos oriundos da relação entre Psicologia e a especificidade dos cenários educacionais. Consideramos pertinente 


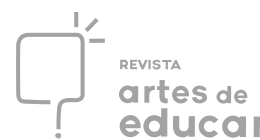

que se produzam oportunidades para a discussão e escuta de narrativas que indicam as ruínas dos regimes instituídos sobre a infância e a juventude. A heterogeneidade das narrativas demanda, de acordo com nosso ponto de vista, uma ruptura na continuidade de nossa relação com contextos educacionais. O sofrimento experimentado por crianças dissidentes e por jovens dissidentes as normas de gênero e sexualidade aponta para o caráter violento das histórias dominantes sobre a formação de si. Narrativas que assombram podem nos mover em direção a crítica aos estabelecimentos e suas instituições. Precisamos politizar as lágrimas não derramadas no passado pelas crianças e jovens perdidas para o dispositivo nominalista da sexualidade, cultivado por práticas que insistem em serem solapadas pelos seus próprios impensados. Benjamin (2015), em uma de suas transmissões radiofônicas para crianças e jovens na Alemanha entre 1927 e 1932, relembra o ritual do julgamento e da confissão de pessoas consideradas praticantes de bruxaria e feitiçaria. Os processos contra bruxas, afirma-nos o pensador, eram a expressão de uma tentativa longa de aprisionamento da humanidade. No ritual da confissão, as pessoas que não conseguiam chorar, previamente presumidas como culpadas, eram condenadas. No século XVI, apenas a confissão era o suficiente para a condenação. A confissão era obtida por intermédio da tortura. Benjamin (2015) assim narra um dos testes utilizados no julgamento de presumidas bruxas e feiticeiros:

Havia por exemplo o teste das lágrimas. Se alguém não chorasse de dor durante a sessão de tortura, então isto era prova de que o réu tinha pacto com o diabo - e de novo foi preciso que se passassem 200 anos, até que os médicos realizaram a mera observação e ousaram afirmar que o ser humano não chora quando sente uma dor muito intensa. (p.136).

Lutar pelo fim dos processos contra bruxas foi crucial para a libertação da humanidade, afirma o pensador para seus ouvintes juvenis. Por quanto tempo ainda recolheremos as lágrimas e as dores intensas sem lágrimas da infância repartida entre especialistas e moralistas da educação? Quantos esforços precisaremos fazer para interromper a colonização da experiência de si quando evocarmos o dispositivo de sexualidade sobre crianças e jovens em práticas educacionais? Narrar, recolher as narrativas, instituir novas políticas de pesquisa e novos campos problemáticos em torno da sexualidade e do gênero podem ser a interrupção de que necessitamos dos regimes que produzem adultos desconfiados e crianças que não podem brincar. Moralismo que mata e entristece ao mesmo tempo em que se reitera como saber. A Psicologia pode contribuir eticamente para a produção de outras narratividades sobre a infância e a juventude. Primeiramente, precisamos acatar o nosso assombro. Há algo clamando por um reconhecimento político. Talvez seja o caráter fabricado de nossas categorias e de nossas perspectivas. Talvez sejam as lágrimas que ainda não derramaram, talvez sejam as lágrimas que nunca derramarão. 


\section{REFERENCIAS:}

AGAMBEN, G. Profanações. SP: Boitempo, 2007.

ANDRADE, L.N. de. Travesti: ser doutora e educadora e possível. In: BENTO,B; FELIXSILVA, A.V. (Org.). Desfazendo gênero: subjetividade, cidadania, transfeminismo. Natal: EDUFRN, 2015, p. 53-83.

BENJAMIN, W. Reflexões sobre a criança, o brinquedo e a educação. SP: Duas Cidades, Ed.34, 2002.

BENJAMIN, W. Rua de mão única: Infância Berlinense:1900. Belo Horizonte: Autentica Editora, 2013.

BENJAMIN, W. A hora das crianças: narrativas radiofônicas . Rio de Janeiro: Nau Editora. 2015.

BUTLER, J. Relatar a si mesmo: critica da violência ética. Belo Horizonte: Autentica Editora, 2015.

CORNEJO, G. La guerra declarada contra el nino afeminado: una autoetnografia "queer". Iconos, Quito, n.39, jan.2011. Disponivel em: http://dx.doi.org/10.17141/iconos.39.2011.747. Acesso em: 30 abr.2017.

FOUCAULT, M. A história da sexualidade: a vontade de saber. Rio de Janeiro: Edicoes Graal, 1997.

GAGNEBIN, J.M. História e Narração em Walter Benjamin. São Paulo: Perspectiva, 1994.

PELBART,P.P. Experiencia e sujeito. In: MUCHAIL, S.M.;FONSECA,M.A. da; VEIGANETO,A. (Org.). O mesmo e o outro: 50 anos de Historia da Loucura. Belo Horizonte: Autentica Editora, 2013. p.45-57.

PRECIADO, Beatriz. Multidões queer: notas para uma política dos "anormais". Rev. Estud. Fem., Florianópolis , v. 19, n. 1, p. 11-20, abr. 2011 . Disponível em $<$ http://www.scielo.br/scielo.php?script=sci_arttext\&pid=S0104-

026X2011000100002\&lng=pt\&nrm=iso>. acessos em 30.abr. 2017. http://dx.doi.org/10.1590/S0104-026X2011000100002.

\footnotetext{
i Professor Associado do Departamento de Psicologia/ Instituto de Psicologia/ Universidade Federal Fluminense/ Professor do Programa de Pos graduação em Psicologia: Estudos da Subjetividade da UFF.
} 